\title{
O VALOR DE UMA GERAÇÃO
}

Marco Aurélio Nogueira

Vistas pelo ângulo das ideias e das formas de inserção reflexiva no mundo, as gerações nos ajudam a desvendar a vida.

Agregações particulares formam-se sem cessar, dando ordem e sentido ao tecido social. Muitas deixam pegadas e sulcos no tempo. Outras, em número menor, chegam a exercer influência tão poderosa que impossibilitam qualquer explicação totalizante que não as leve em consideração. A geração de 1870 no Brasil, a do entre-guerras na Europa, a de 1968 no mundo, como sabemos, disseminaram estilos de viver e pensar, certos nódulos ideais, modos de se pôr na vida, fazer política, ir ao teatro ou ao cinema, organizar uma biblioteca, fixar uma maneira de amar e constituir família. Fizeram história.

Com intensidade menor, sem potência para plasmar uma época, diferentes gerações de intelectuais respondem pelo trabalho de fornecer autoconsciência às sociedades, ajudá-las a se reconhecer como cultura, a se organizar como arte, filosofia e ciência, a se encontrar com a política, o Estado, a escola. Se conseguirmos individualizá-las e compreen- 
dê-las, teremos acesso privilegiado a dimensões essenciais de uma experiência coletiva.

Gerações intelectuais são feitas de amizades e companheirismo, mas não só. São feitas também de instituições e pontos de referência, simbólicos e materiais. Por essa via, trazem consigo rusgas, atritos, disputas, às vezes dilacerantes. Amizades podem até se desfazer, mas as gerações seguem em frente, como se protegidas por uma rede oculta de pequenas e grandes cumplicidades que operam no subterrâneo, ligando as agregações e cauterizando as feridas abertas pelos choques e golpes da vida.

Gerações intelectuais não são comunidades amorfas, desfibradas, insossas. São comunidades imperfeitas, forjadas no fogo. São internamente diferenciadas, múltiplas e plurais, no sentido de que, nelas, nem todas as luzes brilham ao mesmo tempo ou com a mesma intensidade. De algum modo, os representantes de uma geração dividem 24 entre si o trabalho que estão fadados a fazer. Deixam o ar de sua graça, por isso, tanto pelo que é pensado e realizado por um ou outro de seus membros mais destacados, quanto pelo produto derivado do esforço menos perceptível do conjunto.

A morte abrupta, precoce e repentina de Gildo Marçal Bezerra Brandão, ocorrida em 15 de fevereiro de 2010, abalou ao menos uma das gerações intelectuais que se lançaram no universo das ideias e da política no início da década de 1970, no Brasil. Tenho orgulho de pertencer a ela e de ter podido trilhar um longo trecho de estrada com ele. Conhecemo-nos em 1973, praticamente no mesmo momento inaugural: o início de uma carreira acadêmica, a descoberta do jornalismo, o encontro com a política, a formação da identidade ideológica e das preferências intelectuais. Nossos símbolos e pontos de referência logo se tornaram comuns: o marxismo, a esquerda, Lukács, Gramsci, Visconti, a USP, a Escola de Sociologia e Política, a Unesp a 
Livraria e Editora Ciências Humanas, o PCB, a revista Temas de Ciências Humanas, o PCI, a Folha de S.Paulo, o jornal Voz da Unidade, o ensino, a pesquisa, a democracia, depois o Cedec, a revista Lua Nova, a Anpocs, a Revista Brasileira de Ciências Sociais.

Fizemos ou participamos de tantas coisas juntos que é no mínimo estranho que esteja eu aqui, sozinho, subscrevendo esse registro memorialístico em tom de homenagem póstuma.

Gildo foi, à sua maneira, um intelectual à moda antiga que soube se atualizar e se abrir para o mundo. "Antigo", porque enciclopédico, avesso a especializações unilaterais. Adorava conversas e polêmicas, que lhe eram o sal da vida. Teve fases noctívagas extremas, boêmias, animadas por bares e reuniões, como todo bom intelectual que se preze. Transgrediu então todas as rotinas e todo manual de bom senso, o que pode ter contribuído para debilitar ainda mais seu organismo permanentemente fragilizado, mas que, certamente, o levou para as regiões etéreas do espírito e das utopias, a abraçar suas musas. Era "antigo", também, pelo que condensava em si de politicidade: o reconhecimento do valor em si da política, seja como atividade e espaço associados ao poder e à comunidade humana, seja como atitude diante dos outros, postura diante da vida, modo de ser intelectual. Tudo o que fez de mais significativo como docente, pesquisador, escritor, organizador cultural e homem de ideias foi uma tradução criativa dessa centralidade da política nele mesmo.

Política feita de aproximações e reunião, mais que de disputas ou separação. Esforço para perfurar as grossas vigas da história. Tenacidade, paciência e fôlego. Pessimismo da inteligência muitíssimo bem temperado com doses empolgantes de otimismo da vontade. Uma mente aberta, crítica, curiosa, propensa ao diálogo como razão última da convivência. 
Fez certamente, como todos, algumas escolhas erradas. Amargou períodos de baixas e dificuldades, correu o risco de permanecer perambulando pelas margens dos subsistemas. Nunca o vi, porém, esmorecer ou reclamar. Sempre soube esperar um novo nascer do dia, circunstâncias mais favoráveis, outras oportunidades. Cresceu e avançou assim, quase em silêncio.

Sua geração - que é a minha e a de tantos outros que frequentam o Cedec, que leem ou lerão Lua Nova, que têm a política como valor - deixou pegadas na história brasileira. Sem cabotinismo (ah, como ele adorava essa palavra!) e sem falsas modéstias, ainda que também sem o devido reconhecimento. Foi uma geração que viveu com intensidade. Experimentou de tudo, imaginou cenários épicos, abriu muitas sendas. Atracou-se com a resistência à ditadura e a transição democrática, com a luta armada e a luta eleitoral, jogou-se nos espaços da intransigência e da negociação,

26 construiu instituições. Absorveu praticamente todos os influxos dessa movimentação, combinados em maior ou menor medida com as ressonâncias e os desdobramentos de 1968, da Tchecoslováquia, do eurocomunismo, da cristalização da ideia de democracia como valor universal, das novas formas do movimento operário, da questão feminina, da reconstitucionalização do país, do Muro de Berlim, do desaparecimento dos partidos comunistas, da vida líquida e informacional. Não foi uma geração que se limitou a assistir a tais acontecimentos portentosos. Pôde participar deles, interferir neles, protagonizá-los. Talvez por isso tenha ido tão longe e possa, hoje, proclamar sua personalidade geracional.

Por opções e armadilhas da vida, Gildo chegou relativamente tarde ao trabalho acadêmico mais sistemático. Entre 1973 e 1989, o jornalismo e a política o consumiram. Trabalhou na Folha com Cláudio Abramo, dirigiu o jornal comunista Voz da Unidade de 1980 a 1981, ajudou a editar o Diário do Grande ABC. Especialmente na Voz, com a contri- 
buição de um seleto grupo de colaboradores e companheiros, viveu uma intensa aventura intelectual, de que pude ser testemunha e partícipe. Entregou-se a ela com um sentido de missão que jamais cedeu à tentação do fanatismo ou da prepotência e que buscou explorar ao máximo as oportunidades que se abriam - mas que logo se fechariam - para uma reinvenção do comunismo, de sua cultura, de sua linguagem, de sua forma de comunicação com a sociedade. Perdeu uma batalha, mas nenhuma guerra.

Incorporou-se então ao Departamento de Ciência Política da USP em 1989, defendeu seu doutoramento em 1992, ficou na Universidade de Pittsburgh (EUA) entre 1995 e 1997, defendeu a livre-docência em 2004 e pavimentou uma carreira que culminaria, em março de 2010, com as provas que iriam consagrá-lo professor titular. Seu percurso em vinte anos foi digno de respeito e admiração. Entregouse de corpo e alma ao ensino e à pesquisa. Deu aulas, orientou, formou discípulos e companheiros de ideias, ajudou a estruturar e a impregnar de sentido os ambientes em que trabalhou. Permaneceu duas gestões (4 anos) como dirigente da Anpocs e editor da Revista Brasileira de Ciências Sociais. Sua livre-docência, Linhagens do pensamento político brasileiro, converteu-se não só num livro maravilhoso, em 2008, como também deu origem a uma linha de pesquisa que cresceu em importância, ultrapassou a USP, para desaguar no Cedec, onde está agora, com todas as suas promessas e possibilidades.

Seu primeiro livro, A esquerda positiva. As duas almas do Partido Comunista. 1920-1964, publicado em 1992, ajudou centenas de pessoas - militantes, dirigentes, analistas, pesquisadores - a rever a história e o significado dos comunistas na política e na cultura nacionais, que Gildo conhecia por dentro, por experiência própria. O partido clandestino que jamais desistiu da busca da legalidade mas que, paradoxalmente, alma dilacerada, pareceu ter-se deixado levar 
mais por seus momentos de reclusão e fechamento do que pelo ar puro que pôde respirar, num processo que forjou mentalidades, personalidades, taras, virtudes, estilos, visões do mundo. E terminou por aprisionar o PCB numa duplicidade que o atravancou inexoravelmente: partido positivo, interessado generosamente no encontro de soluções realistas para o país, misturado com restos duradouros de partido-seita, impermeável à crítica, à diferença, à renovação. Ao final, um patrimônio duramente acumulado se desperdiçou. Sua lenta e progressiva derivação para a margem da vida foi um epitáfio doloroso.

Mas não necessariamente para a geração político-intelectual de que fez parte Gildo Marçal. A parte mais expressiva dela soube se atualizar, seguir adiante, escapar daquele círculo de fogo em que havia apostado parte da vida. Foi em frente com um acumulado de experiências, um modo de ver as coisas, um jeito de fazer política, uma linhagem de 28 pensamento. Marcas do tempo, cicatrizes, cacoetes, léxico particular, um cadinho que identifica.

Há legados nessa história. Coletivos e particulares. Cada um cavou também sua trincheira pessoal, alargou-a e consolidou-a com o passar dos anos, bebeu outras águas e elixires, frequentou outras tribos e lugares, cultuou, quem sabe, outros deuses. Nada se perdeu.

Gildo Marçal Brandão deixou-nos mais que uma obra no sentido formal da expressão. Deixou-nos um exemplo de conduta intelectual, de dedicação e celebração da vida, sabedor que era da sua temporalidade e, ao final, da sua finitude. É uma herança múltipla, composta de filhos, pessoas, amigos, ideias, gestos e atitudes. Por isso mesmo, destinada a se reproduzir. 